\title{
Aniversário dos filhos: juntos ou separados? Repercussões do divórcio na perspectiva dos pais
}

\section{Children's birthday: together or apart? Repercussions of divorce from parent's perspective}

\section{Cumpleaños de los hijos: juntos o separados? Repercusiones del divorcio en los hijos}

\section{Michelle Christof Gorin*}

Pontifícia Universidade Católica do Rio de Janeiro - PUC-Rio, Rio de Janeiro, Rio de Janeiro, Brasil

\section{Terezinha Féres-Carneiro**}

Pontifícia Universidade Católica do Rio de Janeiro - PUC-Rio, Rio de Janeiro, Rio de Janeiro, Brasil

\section{Rebeca Nonato Machado***}

Pontifícia Universidade Católica do Rio de Janeiro - PUC-Rio, Rio de Janeiro, Rio de Janeiro, Brasil

\section{RESUMO}

Este artigo discute a percepção dos pais a respeito das repercussões do divórcio nos filhos, tendo como foco a comemoração do aniversário destes. Foi desenvolvida uma pesquisa qualitativa com quatro pais e quatro mães separados, a partir da realização de entrevistas semiestruturadas. Os resultados foram estudados de acordo com o método de análise de conteúdo. Verificou-se que o divórcio implica em uma ferida narcísica importante para os sujeitos envolvidos, podendo gerar uma tendência a recalcar as representações do ex-cônjuge. Esse movimento pode dificultar a elaboração do luto pelo fim da conjugalidade, trazendo dificuldades centrais para o exercício da parentalidade, uma vez que os filhos permanecem envolvidos em conflitos. Os filhos podem experimentar uma divisão em suas vivências com seus dois objetos de amor, pai e mãe, o que é ilustrado pelas comemorações de aniversários realizadas pelos genitores, em alguns casos em conjunto, e em outros, em separado.

Palavras-chave: parentalidade, divórcio, aniversário, recalcamento, divisão.

\section{ABSTRACT}

This article seeks to discuss the repercussions of parental divorce on children from the parents' perception. The current study aims to discuss parents' perceptions about the repercussions of divorce on their children, focusing on children's birthday celebrations. The authors conducted a qualitative research with four fathers and four mothers, performing semi-structured 
interviews and studying the results using the content analysis method. Evidence shows that divorce inflicts a major narcissistic wound in the subjects involved, which may generate a tendency to repress representations of the former spouse. This movement may hinder the elaboration of grief caused by the end of marital relations, since the children remain involved in conflicts. The children may suffer a division in their experiences with both love objects, father and mother, a condition illustrated by birthday celebrations held by parents, in some cases together, and in other, separately.

Keywords: parenthood, parenting, divorce, birthday, repression, division.

\section{RESUMEN}

Este artículo pretende discutir las repercusiones del divorcio en los hijos, a partir de la percepción de los padres. Em este artículo se analiza la percepción de los padres sobre el impacto del divorcio en los niños, centrándose en la celebración del cumpleaños de éstos. desarrolló una investigación cualitativa con cuatro padres y cuatro madres separados, a partir de la realización de entrevistas semiestructuradas. Los resultados fueron estudiados según el método de análisis de contenido. Se verificó que el divorcio implica en una herida narcisista importante para los sujetos involucrados, lo que puede generar una tendencia a reprimir las representaciones del ex-cónyuge. Ese movimiento puede dificultar la elaboración del luto por el fin de la relación conyugal, aportando dificultades centrales para el ejercicio de la parentalidad, una vez que los hijos permanecen involucrados en conflictos. Los hijos pueden experimentar una división en sus vivencias con sus dos objetos de amor, padre y madre, lo que es ilustrado por las celebraciones de cumpleaños realizadas por los genitores, en algunos casos juntos, y en otros, por separado.

Palabras clave: parentalidad, divorcio, cumpleaños, represión, división.

O divórcio, entendido aqui como rompimento da relação conjugal, demanda reflexões e adaptações nas relações intersubjetivas do núcleo familiar, na organização do dia a dia, e também nas questões intrasubjetivas. Apesar de ser bastante comum o fim do casamento, legalmente constituído ou não, continua a trazer desafios para todos os envolvidos - o próprio casal, filhos, novos cônjuges, parentes, entre outros - por se constituir como um momento de ruptura no grupo, independentemente do arranjo familiar.

Nesse sentido, é importante discriminar as esferas da conjugalidade e da parentalidade, uma vez que a separação é do casal e não da prole, de forma que os genitores permanecem um casal parental. Constituise como um desafio continuar a se relacionar com ex-cônjuge a fim de compartilhar o cuidado e as responsabilidades com os filhos.

Os conflitos e angústias que essas vivências despertam se refletem na forma como a parentalidade poderá ser exercida. As crianças são capazes de perceber os cuidados que recebem de seus pais, atribuindo valor significativo a essas experiências, de forma que o afeto das relações se mantém como pilar da constituição familiar atualmente, independente do arranjo conjugal (Féres-Carneiro et al., 
2015). Assim, a relação entre os ex-cônjuges é central na forma pela qual os filhos vivenciam os conflitos.

Partindo dessas postulações, este artigo tem como objetivo investigar as repercussões do divórcio nos filhos a partir da percepção dos pais. A formação e o rompimento da conjugalidade e suas implicações para cada um individualmente e para o exercício da parentalidade são temas centrais nesse debate. Os aniversários dos filhos, momentos que dizem respeito a todo grupo familiar, são usados como exemplo significativo de como as relações após o divórcio conjugal podem se estabelecer. Para atingir o objetivo formulado, desenvolvemos uma pesquisa de campo e utilizamos os referenciais teóricos da psicanálise e da psicoterapia de família em suas vertentes sistêmica e psicanalítica.

\section{A formação e o rompimento da conjugalidade}

O narcisismo é originalmente descrito como o amor pela imagem de si mesmo, através do mito de Narciso, que admira a si próprio. Freud (1914/2010), por meio desse conceito, discute os investimentos libidinais feitos pelo sujeito no próprio Eu e nos objetos. O autor destaca que é preciso amar para não adoecer, para isso, desloca-se parte da libido do Eu para um objeto externo. O amor-próprio está vinculado à escolha objetal, uma vez que ao ser amado, a escolha narcísica por aquele objeto é satisfeita.

A partir de Freud (1914/2010), vemos a relação entre a escolha amorosa e o narcisismo do sujeito, de forma que a ruptura da relação conjugal terá consequências narcísicas importantes. Uma vez que o sujeito ama seu cônjuge e é amado por ele, seu narcisismo está investido nesta relação amorosa e é investido por ela, seu término é, então, vivido como uma ferida narcísica.

Moguillansky e Nussbaum (2011) apontam, a partir do conceito de vínculo, que a construção da relação intersubjetiva implica em uma mudança narcísica ilusória para o sujeito, uma vez que há uma fantasia de se fusionar ao objeto de amor, que seria idealmente igual ou complementar ao sujeito. Essa ilusão consiste na crença de ambos os membros do casal de terem se tornado apenas um com seu amor. Nesse cenário, é possível compreender que o divórcio conjugal traz sérias repercussões na subjetividade de cada um dos cônjuges. Os investimentos libidinais precisam ser reorganizados a partir do fim do casamento, demandando trabalho de elaboração psíquica. Freud (1915/2010a) descreve a reação natural à perda de alguém como um processo de luto, podendo ser muito doloroso para o sujeito. É comum haver por um período um desinteresse pelo mundo externo e, aos poucos, a realidade mostra que não existe mais o objeto amado, e a libido precisa sair desse investimento à procura de outros objetos. 
Esse deslocamento da libido é muito sofrido para o sujeito, que vive a contradição entre a oposição às mudanças de seus investimentos e a realidade que se apresenta.

O objeto perdido se mantém no psiquismo do sujeito e tudo que está remetido a ele ganha ênfase. É aos poucos que a libido se desliga desse objeto para poder se ligar a outro (Freud, 1915/2010a). No caso do divórcio conjugal, os cônjuges perdem o objeto amado e precisam, através do luto, elaborar a perda para poder investir em novos relacionamentos. Inibições e falta de interesse são comuns nessa fase em que o Eu está tomado pelo processo de luto.

Quando há desilusão amorosa, pelos desencontros inevitáveis da vida a dois, Moguillansky e Nussbaum (2011) apontam que é comum a sensação de não conhecer o parceiro nesse momento difícil, atrelando as dificuldades a algo que está sendo descoberto. A sensação de fracasso gera a desilusão, assim, sente-se que há algo negativo no outro, que foi escondido e que agora, encontrado, desperta ódio e decepção.

De acordo com os autores, é muito difícil renunciar à idealização do objeto amado, mantendo-se assim a esperança de que o amor dure para sempre. Dessa forma, a relação é regida por uma lógica binária, ou se está dentro desse vínculo ilusório ou não. Quando o vínculo se rompe, por divórcios ou conflitos de maneira geral, surge um sentimento de estar fora do amor, muito longe do ideal, gerando a sensação de fracasso.

Freud (1915/2010a) destaca que no luto normal todas as memórias e lembranças do objeto perdido, ainda investidas libidinalmente, são confrontadas com a realidade de que não há mais aquele objeto. Com o tempo, em nome da satisfação narcísica em manter sua própria existência, rompe-se o investimento objetal para se investir em novos objetos. Assim, para viver o luto é necessário se relacionar de alguma forma com o que se perdeu, pois as memórias referidas ao objeto perdido são essenciais para que o sujeito possa se despedir dele.

No entanto, permanecer vinculado ao amor que se perdeu, durante o longo e doloroso processo de luto, pode não ser possível para algumas pessoas. É comum que, como defesa, se tente afastar dos pensamentos toda e qualquer lembrança ligada ao objeto perdido. Freud (1915/2010b) destaca o mecanismo de recalque como o movimento de manter no inconsciente aquilo que é insuportável ao consciente, protegendo o sujeito do desprazer que essa representação gera através dessa divisão. Assim, diante de uma perda que gera muito sofrimento, é possível que se tente recalcar tudo que se relaciona ao que foi perdido para evitar mais dor, porém, o processo de luto fica mais difícil. 
Divórcio dos pais: repercussões na vida dos filhos

Pesquisa realizada por Brito (2007), com filhos de pais separados, teve como objetivo aprofundar a compreensão das vivências destes na separação dos pais. Os resultados mostram não só que os que tiveram seus pais separados ainda criança não possuem memória sobre todos os membros vivendo na mesma casa, mas que também conhecem apenas o lado da história do genitor guardião. Já outros, apesar de crescidos, encararam o divórcio como algo traumático, pois não percebiam conflitos entre os pais. A autora destacou que os filhos sentem muito a saída de um dos genitores de casa, chegando a apresentar sintomas somáticos. Além disso, os filhos não viam possibilidade de conversarem com seus pais sobre a separação.

O estudo de Brito (2007) sinaliza que a maioria dos pesquisados se ressente pela separação dos pais e considera como momentos marcantes os vivenciados com eles quando ainda unidos. Indicam também que os jovens ou as crianças que presenciam os conflitos conjugais anteriores ao divórcio julgam a separação como decisão correta. Aqueles que convivem com ambos os genitores sentem falta da época em que os pais mantinham a relação conjugal. Para a autora, os filhos que apresentam menor número de queixas são os acolhidos tanto na casa da mãe quanto na do pai. Inclusos na realidade de ambos os genitores, continuam a sentir-se como o centro das atenções familiares.

No mesmo estudo, muitos dos pesquisados reclamam do fato de terem sido colocados no centro das brigas dos pais, rompendo com a ideia de que o divórcio é a solução para acabar com os conflitos. Dentro dessa perspectiva, evidencia-se um ponto de incômodo, a desqualificação de um dos ex-cônjuges.

Juras e Costa (2011) apontam que os filhos que vivenciaram o divórcio dos pais percebem que, após a ruptura, eles não se relacionam bem e seu encontro gera conflito. Estes envolvem as crianças de diversas formas, atribuindo a elas responsabilidades que não cabem em seu papel familiar e sua idade. Assim, os filhos no centro dessas questões vivem conflitos de lealdade, são parte de comunicações indiretas entre os ex-cônjuges, ocupam posições hierarquicamente superiores na família, entre outras situações que são vividas com sofrimento.

Nesse sentido, as autoras destacam que na tentativa de compreender o conflito, os filhos podem demonstrar agressividade, insegurança e depressão como expressão do afeto envolvido nessa vivência, além de racionalizar buscando respostas para os dilemas, tornando-se muito importante atentar para o melhor interesse da criança, através da escuta da mesma.

Raposo et al. (2011) apontam que os problemas decorrentes do divórcio, especialmente para os filhos, não se relacionam à separação 
dos pais em si, mas à mudança estrutural que a família vive. Assim, o modo como os pais vivem a situação se relaciona à competência parental que terão nessa circunstância. Para os autores, a resolução de conflitos entre os membros do casal parental, a coparentalidade positiva e o estado psicológico dos pais, entre outros, são aspectos centrais no modo como a criança viverá o divórcio.

Para os autores, é importante nos debruçarmos sobre os aspectos positivos que o divórcio pode trazer aos filhos, e não apenas olhar os pontos negativos. Para eles, os efeitos negativos da separação ocorrem nos primeiros anos, em um momento de crise e de reorganização subsequente. Mas o divórcio também pode ser vivido como um momento importante no desenvolvimento, que estimula a adaptação e a resiliência ao longo de tantas transições.

De maneira geral, os autores expostos nessa articulação teórica explicitam as consequências e as marcas que envolvem a identidade pessoal e social das crianças e adolescentes, não só em períodos que antecedem o processo do divórcio, mas também durante as disputas litigiosas. Os filhos vivenciam os conflitos relacionais, sentindo-se, muitas vezes, culpados pela situação ou como estorvos à felicidade dos genitores. A não participação no processo aprofunda essas sensações, independentemente da idade em que se encontra o sujeito implicado nos embates entre os pais.

\section{Método}

Participantes

Participaram do estudo quatro mães e quatro pais, sujeitos independentes, oriundos das camadas médias da população carioca, separados há no mínimo um ano e no máximo sete anos, com filhos entre oito e 12 anos que convivem com ambos os genitores. A escolha da faixa etária dos filhos ocorreu considerando-se ser este um período de dependência e de convivência com os pais, no qual surgem questões individuais e de autonomia. A delimitação em relação ao tempo do divórcio foi estabelecida tendo em vista a importância de que os participantes alcançaram alguma estabilidade, após a separação, e de, ao mesmo tempo, estarem próximos o bastante para levantar as questões suscitadas à época, além dos seus desdobramentos atuais.

As mães e os pais foram nomeados em grupos separados de 1 a 4 . A idade das mães variou de 35 a 57 anos e o tempo de separação de dois anos a seis anos, com filhos entre dez e 12 anos. A idade dos pais variou de 38 a 57 anos e o tempo de separação de dois anos e sete anos, com filhos entre oito e 12 anos. Vale ressaltar que os participantes Mãe 1, Mãe 3, Mãe 4 e Pai 2 têm apenas um filho, os 
participantes Mãe 2, Pai 3 e Pai 4 têm dois filhos e o participante Pai 1 tem três filhos.

\section{Instrumento e procedimentos}

Os participantes foram entrevistados individualmente, tendo um roteiro semiestruturado como base, elaborado a partir da revisão da literatura sobre a percepção dos pais sobre a parentalidade e sobre a vivência dos seus filhos no pós-divórcio. As entrevistas foram gravadas e transcritas.

\section{Cuidados éticos}

O projeto de pesquisa foi aprovado pelo Comitê de Ética da instituição onde foi desenvolvido e todos os participantes assinaram o Termo de Consentimento Livre e Esclarecido, autorizando a divulgação dos resultados em ensino, pesquisa e publicação.

\section{Resultados e Discussão}

Para apresentação e discussão dos resultados as mães foram nomeadas de Mãe 1 a Mãe 4, e os pais de Pai 1 a Pai 4. As entrevistas foram submetidas à análise de conteúdo, conforme proposta por Bardin (2011). Essa proposta possibilitou a leitura do material coletado a partir das mensagens e conteúdos que os relatos revelaram. Do relato dos participantes emergiram cinco categorias: Os comportamentos dos filhos frente ao divórcio na perspectiva dos pais, As festas de aniversário dos filhos: o encontro dos ex-cônjuges, O fim da conjugalidade para as mulheres, O fim da conjugalidade para os homens e A experiência da parentalidade após o divórcio. Neste artigo serão apresentadas e discutidas as duas primeiras categorias citadas.

Os comportamentos dos filhos frente ao divórcio na perspectiva dos pais

Cada criança reage de forma singular frente ao divórcio dos pais, recebendo forte impacto da forma como os adultos estão vivendo o momento. A maioria das crianças não se queixou do divórcio por razões distintas. Mesmo insatisfeitas com a situação, de acordo com os genitores, três delas buscaram evitar conflitos na família (Mãe 3, Mãe 4, Pai 3). 
Essa questão dele querer evitar atrito o tempo todo. Mas ele é bem... sem dúvida alguma, ele gostaria de ter mais tempo com o pai. (Mãe 3)

Será que eu volto? Aí, fui perguntar pra ela. "P, você gostaria que seus pais voltassem?" Ela falou não. Perguntei: "Você não tem tristeza, não tem..." "Não, mãe, é muito chato, meu pai é muito chato, não queria vocês dois juntos, ele tem uma namorada, eu quero que ele fique com a namorada dele". Aí eu falei: "E eu posso namorar?" Aí ela falou: "Pode, você tem que ser feliz". (Mãe 4)

O assunto é mais velado, bem fechado, me sinto até desconfortável de ver que eles não tão à vontade de falar nada de lá aqui. (...) (...) Isso que eu me sinto mal, eles não se sentem nem à vontade para falar disso. (...) É um assunto delicado, acho que aí eu falhei, eles não se sentem à vontade de falar nada da mãe, acho que o contrário também. (Pai 3)

Esses dados corroboram os encontrados por Juras e Costa (2011), ao destacarem que a maior parte dos filhos de pais separados percebe que seus genitores não mantêm um bom relacionamento após o divórcio. Nesse sentido, os autores destacam que os filhos, frente aos conflitos dos pais, podem ficar em uma posição difícil, que desperta diversos sentimentos.

Ao tentar evitar conflitos entre os pais, segundo a percepção dos genitores, os filhos demonstram perceber que a situação está sendo difícil não apenas para eles, mas também para os próprios genitores. De acordo com Freud (1914/2010), a relação amorosa está diretamente relacionada ao narcisismo do sujeito, uma vez que engloba a escolha e o investimento no objeto de amor e a experiência de ser amado pelo mesmo objeto. Assim, a ruptura dessa relação é como uma ferida narcísica, gerando muito sofrimento para os membros do ex-casal. O fracasso e a desilusão ganham ênfase na subjetividade do sujeito e, de forma decorrente, surgem sentimentos de ódio e de decepção em relação ao ex-cônjuge (Moguillansky \& Nussbaum, 2011).

No processo de luto, a realidade mostra que o objeto de amor não existe mais e é necessário reorganizar os investimentos libidinais (Freud, 1915/2010a). A delicadeza da situação do divórcio, percebida pelos filhos ao se preocuparem com possíveis conflitos, marca que o processo de luto ainda está ocorrendo e há algo dessa ferida narcísica que ainda persiste dentro dos pais.

Voltando à questão de os filhos, na percepção dos pais, não se queixarem, o Pai 2 percebeu a insatisfação de seu filho quando ele relatou ter sentido sua falta. Apenas a Mãe 1 apontou um exemplo de sua filha criticando abertamente a separação dos pais. Outros dois 
pais (Pai 1 e Pai 4) e uma mãe (Mãe 2) não destacaram queixas dos filhos.

Fala que tava com saudade, de vez em quando, quando eu devolvo ele, e ele diz que vai ficar com saudades. (Pai 2)

Ah, mas não quero duas casas, não quero ir para a casa do meu pai, quero que meu pai venha para cá, você deixa meu pai voltar para casa? meu pai não volta porque você não deixa. (Mãe 1)

Esses dados corroboram os resultados encontrados por Brito (2007), em pesquisa com filhos de pais separados, quando apontam que a maioria se ressente de alguma forma pelo ocorrido. Seja pela reclamação explícita, seja pela saudade de um dos genitores, seja pela ausência de queixas pela preocupação com os pais, a maior parte dos filhos, de acordo com a percepção dos pais, demonstrou viver o divórcio de maneira sofrida, envolvida em conflitos, explícitos ou não. Como apontado pela autora, a reclamação sobre ficar no meio dos conflitos dos genitores e a impossibilidade de conversar com os pais, sobre o divórcio, podem seguir ocorrendo como repercussões importantes da separação conjugal para a prole.

Os relatos dos participantes evidenciam que as mudanças, após o divórcio dos pais, provocam sentimentos nos filhos, como a falta de um dos genitores. Como apontado por Raposo et al. (2011), as repercussões do divórcio para os filhos estão mais ligadas às mudanças em si pelas quais a família passa, de ordem estrutural, e não ao divórcio efetivamente. A partir disso, é a forma de exercer a parentalidade nessa reorganização familiar que se relaciona com a forma que os filhos vivem esse processo.

Os resultados da pesquisa mostraram que metade dos filhos, de acordo com a percepção dos pais, não fala sobre um genitor para o outro. Nesses casos, segundo os participantes, parece que não o fazem para atender ao pedido de um dos pais ou devido a uma atmosfera familiar que impossibilita tal assunto.

Graças a Deus ela nunca trouxe nada de lá para mim. Também nunca levou. Nunca fala, ainda bem (risos). Ela separa completamente. E eu não pergunto nada e não ligo. (...) Eu também separo muito. O que que você fez hoje não. Quando ela chega da casa do pai eu não pergunto o que fez o que que não fez. (Mãe 2)

O assunto é mais velado, bem fechado, me sinto até desconfortável de ver que eles não tão à vontade de falar nada de lá aqui. (Pai 3)

Olha só, o que você faz com ela (namorada do Pai) lá fica lá, porque a mamãe não quer, eu não gosto, eu tenho ciúmes; Ah, 
você tem ciúmes, tenho ciúmes, tô com ciúmes. Sempre conversei com ela e ela sempre entendeu. (Mãe 1)

Um dos problemas que aconteceu aqui foi que a mãe disse que ela tinha que falar tudo que acontecesse aqui, meio complicado do lado de lá. E tudo que era de lá era segredo. A mãe falava você não vai contar nada do que acontecer aqui. Naturalmente, "Ih, Pai, não fala pra mamãe que eu te contei", não podia contar. "Por que não podia?" "Ah, porque ela disse que não pode contar nada do que acontece lá." Eu falei, "Tá bom, pra mim segredo é só quando é errado. Aqui você pode contar tudo. Não faz nada de errado, não faz nada escondido, então pode contar tudo". (Pai 1)

As dificuldades evidenciadas nessas falas e persistentes após o divórcio mostram que o ex-cônjuge pode se tornar um tema velado entre pais e filhos. Há uma evitação do tema, como possível fuga da ferida narcísica que o rompimento conjugal gerou. Assim, quando Freud (1915/2010b) descreve o mecanismo de recalque como o meio para manter inconsciente aquilo que gera desprazer, explica o movimento de algumas pessoas ao tentarem ignorar e apagar tudo que se liga ao objeto perdido. Para alguns pais, parece insuportável manter qualquer tipo de ligação com o ex-cônjuge.

Assim, as restrições dos filhos, impostas pelos pais ou por eles mesmos, sobre intercambiar informações entre os membros do casal parental, corroboram a ideia de que há uma tentativa de recalcar a representação do ex-cônjuge como um movimento de esconder de si mesmo a perda muito sofrida. O narcisismo pode ser tão afetado pela separação que mostra a impossibilidade de lidar com isso conscientemente.

Apenas o Pai 4 ressalta que o filho fala abertamente dos conflitos, gerando problemas para o filho:

Minha ex-mulher se converteu pra outra religião, virou evangélica, e aí ela começa a trazer muitos dogmas da religião dela pra criação, pro convívio dele no dia a dia, e isso tá gerando muito conflito na cabeça dele. Por exemplo, quando ele tá comigo, lá em casa, vou à piscina, lá chamo minha irmã, a gente fica na piscina, começo a beber uma cerveja e ele fala: "Pai, você não pode beber". (Pai 4)

Esses dados confirmam os apontamentos de Juras e Costa (2011) ao destacarem que os filhos podem ser envolvidos em problemas de comunicação e experimentarem conflitos de lealdade como decorrência das dificuldades do divórcio. As mudanças na vida familiar podem trazer para as crianças vivências muito distintas no que diz respeito à convivência com cada genitor. 
Os filhos precisam fazer um grande esforço de elaboração para se relacionar tanto com os contrastes que surgem entre os genitores como com o esforço de um dos pais em recalcar o que está remetido ao outro. Isso pode ser vivido de forma bastante confusa, representando uma divisão para a criança, tanto fora quanto dentro dela.

\section{As festas de aniversário dos filhos: o encontro dos ex- cônjuges}

O divórcio conjugal gera muitas mudanças na vida dos filhos. Toda a rotina e os hábitos familiares se reorganizam e a nova forma de convivência depende muito de como os adultos estão vivendo essa ruptura. Nesse contexto, comemorações de aniversário dos filhos, por representarem um rito tradicional e anual, comum a todos os integrantes da família, são exemplos interessantes para a investigação de como esse processo está sendo vivido pelos pais e, consequentemente, pelas crianças.

Mais da metade dos participantes da pesquisa, cinco dentre os oito, não comemora o aniversário do filho em conjunto com o outro genitor, realizando festas separadas. Dentre eles, o Pai 1 relata que a filha gostaria que a mãe estivesse presente na festa, mas ele não deseja que esse encontro ocorra. Apenas a Mãe 3 relata ter convidado o outro genitor, mas que ele não compareceu por vontade própria:

liiih, ele faz uma festa e eu faço outra. É horrível. (Mãe 4) Sempre eu faço a festa (...). A mãe não vem. Até quer vir, mas eu não quero que venha, porque cria um clima. Os nossos amigos todos ficaram meus amigos, não ficaram amigos dela, todos, sem exceção. E ela brigou com esses amigos, ficou um clima muito ruim. Então, misturar não ia dar certo. (...) Ela gostaria que a mãe viesse. E aí eu digo que não. A mãe fica insistindo pra vir, de propósito, pra criar a coisa... mas não... (Pai 1)

Eu dou uma festinha, bolo aqui, e ela lá e tal. (Pai 3)

Este ano, por exemplo, ele passou comigo o final de semana anterior ao aniversário dele, acho que caiu numa terça-feira, ele ficou comigo no final de semana, a gente comemorou no final de semana. E no final de semana seguinte ela fez uma festa em $C$ (cidade perto), justamente pra não envolver minha família, pra não me envolver, e tá sendo tudo assim, separado. Eu faço uma coisa da minha família e ela faz lá. (Pai 4)

Depois da separação, os aniversários eu organizo e o pai não participou. (...) a gente sempre chama. (...) teve ano que tava 
trabalhando, sempre tem alguma coisa. Não vou falar que não quis, mas sempre tem um motivo. (Mãe 3)

O divórcio pode afetar diretamente o exercício da parentalidade, quando é muito difícil para os pais manterem a convivência após a separação. O encontro entre pais e filhos fica submetido à possibilidade ou não de encontro dos pais, inclusive em situações de comemorações, onde o foco prioritário poderia ser a criança e não os adultos. Os aniversários, como outras situações da vida das crianças, são alterados por conta dos desentendimentos parentais.

Como apontado anteriormente, há um esforço dos pais em recalcar (Freud, 1915/2010b) tudo que diz respeito ao ex-cônjuge, na tentativa de evitar sofrimento. Porém, como destacado pelo mesmo autor, é a partir das lembranças do objeto perdido que se pode retirar o investimento libidinal feito nele, a fim de escolher novos objetos. A tentativa de recalcamento das representações do excônjuge ou do casamento e do seu fim torna o luto um processo mais difícil. Acredita-se que eventos como aniversários, que promovem o encontro com toda a família da criança, trazem à tona o sofrimento envolvido no fim do casamento. Assim, novamente, tenta-se evitar esse encontro, mantendo o ex-cônjuge, o máximo possível, à distância.

Colocamos em questão as repercussões dessa tentativa de recalcamento para os filhos, ou seja, como a prole vivencia a situação em que um dos pais se esforça em apagar o outro de suas lembranças. Como apontado por Freud (1915/2010b), esse mecanismo de defesa contra um forte desprazer gera uma divisão no sujeito, levando para o inconsciente certas representações. Para os pais, comemorações separadas evitam que revivam o divórcio, ao não precisarem reencontrar o ex-cônjuge, mas para os filhos essa divisão pode ser vivida com sofrimento, uma vez que eles têm ambos os genitores como objeto de amor. O exemplo de duas festas de aniversário ilustra essa experiência de divisão que a criança pode viver. Como apontado por Brito (2007), se os conflitos permanecem após o divórcio, os filhos continuam envolvidos em brigas após o fim do casamento dos genitores.

Dentre os participantes, apenas a Mãe 1 e a Mãe 2 e o Pai 2 fazem comemorações de aniversário em conjunto. Sendo que a Mãe 1 apenas por insistência da filha, sendo uma situação difícil para ela.

Não fiz festa, fiz um bolo em casa e ela disse: "Meu pai pode vir? Quero meu pai e minha mãe juntos". Aí eu respirei fundo três vezes e deixei ele ir." (Mãe 1)

É, organizei, ele pagou e chamei. Depois teve outros aniversários sim... (Mãe 2) 
Ele vai até fazer aniversário agora, a gente vai fazer um churrasco no clube, e vai ser junto, a festa. Nunca teve esse negócio de festa separada, nunca teve nada disso, sempre junto. (...) Aí também divide. Meio a meio. (Pai 2)

Esses participantes ilustraram as possibilidades de negociações para realização das comemorações dos filhos em conjunto. Não aparenta ser algo desejado por nenhum dos participantes da pesquisa, mas sim um esforço em nome do melhor interesse do filho. O pedido da filha, da Mãe 1, evidenciou seu desejo de manter apenas uma comemoração para si e pode ser interpretado como uma tentativa de não ter que dividir seu aniversário e a si mesma. Quando as lembranças da conjugalidade e do seu fim são mais suportáveis e elaboradas, é possível conviver com o ex-cônjuge e não tentar recalcá-lo (Freud, 1915/2010b).

Essa vivência conjunta dos pais permite que os filhos vivam menos essa divisão entre os genitores, como ilustrou a fala do Pai 2, ao enfatizar que nunca realizaram festas separadas. Nesse sentido, a realização de festas dos filhos em conjunto ou em separado aponta para maior ou menor possibilidade dos genitores de resolução de conflitos e de coparentalidade positiva, aspectos centrais para a forma como os filhos viverão o divórcio de acordo com Raposo et al (2011). Esses dados corroboram as postulações de Brito (2007) a respeito dos filhos menos queixosos em relação ao divórcio serem aqueles que foram incluídos na vida de ambos os genitores, mantendo-se no centro da família, ou seja, com menos divisões.

Quando isso não ocorre, os filhos podem viver com angústia esses momentos de encontro entre os pais. Chama atenção que três pais (Mãe 2, Mãe 4, Pai 3) notaram que seus filhos ficam tensos em situações em que os pais se encontram.

Ela não reclamou nada, ela não quer que encontre, mas nesse dia tinha que encontrar. (...) Eu não sei. De repente, eu posso ter passado isso para ela, porque eu não quero encontrar, posso ter passado isso. (Mãe 2)

Mas ela nem se queixa nem faz comentário sobre isso. Esse negócio, acho que ela viu tanta briga, tanta confusão, acho que ela não quer ver a gente junto. (Mãe 4)

Eu dou uma festinha, bolo aqui, e ela lá e tal. (...) [- E seus filhos reclamam disso?] I sso que eu me sinto mal, eles não se sentem nem à vontade para falar disso. Se eu disser: "Filhos, preciso falar com vocês", eles já vão tremer na base. (Pai 3)

Esses impasses que vivem os filhos podem se relacionar com a impossibilidade de conversar a respeito do divórcio e com o ressentimento pela separação dos pais, decorrente de tantos 
conflitos, como apontado por Brito (2007), em sua pesquisa com filhos de pais separados. Quando o divórcio gera muito sofrimento para algum dos membros do ex-casal, há uma tendência a recalcá-lo (Freud, 1915/2010b) e também tudo que está ligado a ele, de sua vida e dos filhos também, implicando uma divisão que afasta a separação dos pensamentos conscientes. Em momentos que a realidade enfatiza o divórcio e ele não pode ser recalcado pelo sujeito, conflitos e angústias podem surgir. Nessas situações, em geral de encontro entre os genitores, um conteúdo insuportável vem à tona, remetido às questões narcísicas importantes.

Ao se envolverem no conflito do divórcio, os filhos podem assumir responsabilidades e se preocupar com o bem-estar dos pais, como as falas mostraram. Nesse sentido, metade dos pais participantes (Mãe 1, Mãe 2, Mãe 3 e Pai 4) da pesquisa percebeu seus filhos como maduros, relacionando em parte, tal maturidade, à vivência do divórcio.

Ela disse que bem gostou de um menino, mas disse pra ele que não quer "porque a senhora ia ficar muito preocupada, agora é dona do próprio negócio, com problema no trabalho, tá muito nervosa, muito estressada". [- "Então ela é superpreocupada contigo?"] - "Ela é (...)". (Mãe 1)

Você acha que ela fica mais esperta porque tem que administrar essa situação? Talvez, ela é totalmente autônoma, totalmente autônoma. (...) E ela quer resolver tudo. Então ela chama o táxi e diz "estou no aguardo" (...). A gente vendo o que ia fazer, de repente, ela já tinha entrado, arrumado a mesa. De repente, isso é um fator. (Mãe 2)

$\mathrm{O}$ E é muito maduro, não sei se por que conviveu muito com adulto, sempre foi uma criança bem falante sobre tudo, bem resolvida. (...) Porque de alguma maneira ele se sente o homenzinho da casa, quer saber quem vai, se eu vou receber amigos, onde que eu vou, o que que eu faço. Então, assim, é muito engraçado. Ele é muito atento, vê se trancou a porta, coisas assim, que ele sempre... agora eu tô sem empregada temporariamente, que a menina que trabalhava lá em casa em dezembro saiu, aí ele pergunta: "Mamãe, você quer que eu te ajude a fazer alguma coisa?". E eu penso, eu nunca ofereci ajuda pra minha mãe. Então, ele é muito pró-ativo, solidário. ( Mãe 3)

Ele é maduro, acho que ele amadureceu muito com essa situação toda, ele acabou tendo um crescimento forçado, muita mudança. (Pai 4)

O amadurecimento das crianças, como repercussão do divórcio conjugal, pode ser sinal de que a crise e os conflitos foram vividos de 
maneira resiliente, demonstrando capacidade adaptativa (Raposo et al., 2011). Momentos de transformação intensa podem ser caracterizados como centrais no desenvolvimento, não apenas como fonte de efeitos negativos, mas também como desafios e dilemas que potencializam o crescimento.

As vivências dos filhos após o divórcio dependem muito da forma como o casal parental está lidando com o fim da conjugalidade. As festas de aniversário lançaram luz sobre a importância de elaboração do luto pelo término do casamento por parte dos pais, para que se possa exercer a parentalidade de forma conjunta.

\section{Considerações finais}

O divórcio traz desafios para toda a família, de forma que os envolvidos precisam elaborar o fim da conjugalidade, própria ou dos pais, a fim de reorganizar os investimentos, as relações e o dia a dia. Nesse contexto, o exercício da coparentalidade vem se mostrando como um desafio importante para os ex-cônjuges, podendo alterar as relações pais e filhos no pós-divórcio.

Em relação aos comportamentos dos filhos frente ao divórcio, na perspectiva dos pais, observou-se que cada criança passa por essa situação de sua própria maneira, mas sempre impactada pela forma como está lidando com a separação. Comportamentos de evitação de conflito, de dificuldade de expressar a insatisfação, de impossibilidade de conversar sobre o divórcio ou a respeito de um genitor para o outro foram encontrados de forma recorrente nessa situação.

Nesse sentido, foi destacado que os pais podem sofrer o fim da conjugalidade como uma ferida narcísica, com grande sensação de fracasso e ódio do ex-cônjuge. É necessário passar por um processo de luto, a fim de elaborar a perda do objeto e poder investir em novos objetos. Quando tudo que está remetido ao ex-cônjuge, gera um sofrimento insuportável, foi encontrada uma tendência a recalcar o que diz respeito a ele, como tentativa de esconder todo esse sofrimento.

No entanto, isso dificulta o processo de luto e o sofrimento guardado vem à tona em situações de encontro, como os aniversários dos filhos. Estes são comemorados de forma separada, cada filho tem duas festas de aniversário, uma com o pai e outra com a mãe, nas vivências de cinco dos oito entrevistados. Nesses casos, questionamos se a evitação desse encontro e a tentativa de recalcamento do que se relaciona ao divórcio pode gerar para os filhos uma experiência de divisão. Esta coloca os filhos em uma posição delicada, pois se veem divididos entre seus dois objetos de amor, pai e mãe, no que diz respeito a amar e a ser amado, gerando angústia. 
Assim, apesar de muitas vezes o divórcio ser uma escolha que visa o fim dos conflitos conjugais, é comum os filhos permanecerem em uma situação de divergência após a separação de seus pais. Apesar das dificuldades destacadas nessas vivências, também foram encontrados dados sobre crianças que passaram por essa situação e apresentaram grande resiliência e capacidade adaptativa.

Concluiu-se que o divórcio, de acordo com a percepção dos pais, tem grandes repercussões nos filhos, tendo em vista a necessidade de separar com clareza o que é da esfera da conjugalidade da esfera da parentalidade. Acredita-se que a elaboração do fim da conjugalidade, em vez de seu recalcamento, permite aos pais exercer a parentalidade de maneira mais saudável, evitando que os filhos ocupem posições difíceis diante dos conflitos e se sintam divididos entre seus genitores.

\section{Referências}

Bardin, L. (2011). Análise de conteúdo. Lisboa: Edições 70.

Brito, L. M. T. (2007). Família pós-divórcio: a visão dos filhos. Psicologia: Ciência e Profissão, 27(1), 32-45.

Féres-Carneiro, T., Magalhães, A. S., Henriques, C. R., Machado, R. N., \& Ziviani, C. (2015). Parentalidade contemporânea sob a ótica dos filhos. In T. Féres-Carneiro (Org.), Família e casal: parentalidade e filiação em diferentes contextos ( $p p$. 73-92). Rio de Janeiro: Ed. PUC-Rio/Prospectiva.

Freud, S. (1914/2010). Introdução ao narcisismo. In S. Freud (19141916). Obras completas. Introdução ao narcisismo, ensaios de metapsicologia e outros textos (1914-1916), v. 12, (pp. 13-50). Trad. Paulo César de Souza. São Paulo, Companhia das Letras.

Freud, S. (1915/2010a). Luto e melancolia. In S. Freud (1914-1916). Obras completas. Introdução ao narcisismo, ensaios de metapsicologia e outros textos (1914-1916), v. 12, (pp. 171194). Trad. Paulo César de Souza. São Paulo: Companhia das Letras.

Freud, S. (1915/2010b). Repressão. In S. Freud (1914-1916). Obras completas. Introdução ao narcisismo, ensaios de metapsicologia e outros textos (1914-1916), v. 12, (pp. 82-98). Trad. Paulo César de Souza. São Paulo: Companhia das Letras.

Juras, M. M., \& Costa, L. F. (2011). Divórcio destrutivo e justiça. Revista de Direito Privado, 12, 265-297.

Moguillansky, R., \& Nussbaum, S. (2011). O amor moderno e o amor passional na clínica vincular. Uma contribuição à questão do amor e o ódio na vida amorosa. In R. Moguillansky \& S. Nussbaum, Psicanálise vincular (pp. 216-223). São Paulo: Zagodoni. 
Raposo, H. S., Figueiredo, B. F. C., Lamela D. J., Nunes-Costa, R. A., Castro, M. C., \& Prego, P. (2011). Ajustamento da criança à separação ou divórcio dos pais. Psiquiatria Clínica, 38, 29-33.

\section{Endereço para correspondência Michelle Christof Gorin}

Pontifícia Universidade Católica do Rio de Janeiro - PUC-RJ

Rua Marquês de São Vicente, 225, Gávea, CEP 22453-900, Rio de Janeiro - RJ, Brasil

Endereço eletrônico: migorin@gmail.com

\section{Terezinha Féres-Carneiro}

Pontifícia Universidade Católica do Rio de Janeiro - PUC-RJ

Rua Marquês de São Vicente, 225, Gávea, CEP 22453-900, Rio de Janeiro - RJ, Brasil

Endereço eletrônico: teferca@puc-rio.br

\section{Rebeca Nonato Machado}

Pontifícia Universidade Católica do Rio de Janeiro - PUC-RJ

Rua Marquês de São Vicente, 225, Gávea, CEP 22453-900, Rio de Janeiro - RJ, Brasil

Endereço eletrônico: recanm@gmail.com

Recebido em: 01/12/2016

Reformulado em: 28/03/2017

Aceito em: 03/05/2017

\section{Notas}

* Mestre em Psicologia Clínica na PUC-Rio, Especialista em Psiquiatria e Psicanálise com criança e adolescente no Instituto de Psiquiatria - IPUB/UFRJ e Membro Provisório da SBPRJ .

** Professora Titular do Departamento de Psicologia da Pontifícia Universidade Católica do Rio de Janeiro, Coordenadora do Curso de Especialização em Psicoterapia de Família e Casal da PUC-Rio.

*** Pós-doutoranda em Psicologia Clínica, Pontifícia Universidade Católica do Rio de Janeiro. Doutorada em Psicologia Clínica pela PUC-Rio, Professora do Curso de Especialização em Psicoterapia de Família e Casal da PUC-Rio e Membro Provisório da SBPRJ.

Este artigo de revista Estudos e Pesquisas em Psicologia é licenciado sob uma Licença Creative Commons Atribuição-Não Comercial 3.0 Não Adaptada. 